\title{
Argument Mapping to Improve Student's Mathematical Argumentation Skills
}

\author{
Nonik Indrawatiningsih ${ }^{1}$, Purwanto Purwanto ${ }^{2}$, \\ Abdur Rahman As'ari ${ }^{2}$, Cholis Sa' dijah ${ }^{2}$ \\ ${ }^{1}$ Universitas PGRI Wiranegara, Jl. Ki Hajar Dewantara No. 27-29, Pasuruan, Indonesia \\ ${ }^{2}$ Universitas Negeri Malang, JL. Semarang No 5, Malang, Indonesia
}

\begin{abstract}
This study aims at investigating the difference in students' mathematical argumentation skills before and after the implementation of argument mapping in learning mathematics. It is a quasiexperiment with a quantitative approach. The population was the students of class $X$ Natural Sciences Program in a state senior high school in Pasuruan, East Java, Indonesia. 36 students were involved. The instrument was a mathematical argumentation skills test. Several components were established, adopted from the Revised Bloom's Taxonomy, namely identifying (C1), explaining (C2), drawing conclusions (C3), reducing/adding premises (C4), deducing (C5), and developing/constructing (C6). Students' mathematical argumentation skills were analyzed using the Wilcoxon signed-rank test at $5 \%$ level of significance $(\propto=0.05)$. The findings of this study indicate that students' argumentation skills after the implementation of argument mapping is better than prior treatment $(p=0.002)$. It can be claimed that argument mapping is effective for improving such skills.
\end{abstract}

Keywords - Argumentation, Mathematical Argumentation Skills, Argument maps.

\section{Introduction}

One of the essential aspects of human thinking skills to succeed in life is the ability of argumentation. This

DOI: $10.18421 /$ TEM93-48

https://doi.org/10.18421/TEM93-48

Corresponding author: Nonik Indrawatiningsih,

Universitas PGRI Wiranegara, Jl. Ki Hajar Dewantara No.

27-29, Pasuruan, Indonesia

Email: nonikphy.d@gmail.com

Received: 03 February 2020.

Revised: 27 May 2020.

Accepted: 04 June 2020.

Published: 28 August 2020.

(cc) BY-NC-ND (C) 2020 Nonik Indrawatiningsih at al; published by UIKTEN. This work is licensed under the Creative Commons Attribution-NonCommercial-NoDerivs 4.0 License.

The article is published with Open Access at www.temjournal.com ability is required in resolving most types of problems, as well as a powerful method for assessing the ability to solve problems [1]. It is also linked to reasoning, which is an important portion in learning mathematics. When students "reason", they develop arguments to convince others or themselves of a particular claim; to solve a problem, or to integrate a number of ideas into a more coherent whole [2]. Later, they are expected to put forward a reason accompanied by sufficient data and theoretical support of a mathematical problem, both spoken and written, to present a deep, comprehensive understanding of mathematical concepts [3] . Each student in each subject requires such ability in order to strengthen student's self-understanding [4]. They are encouraged to evaluate arguments, ask questions to clarify arguments, and develop logical arguments [5], [6], formulate questions [7], [8], describe mechanisms and develop arguments [9]. Essentially, arguments are products or outcomes of argumentation that contain several premises and conclusions [3].

Mathematical argument is a logical cognitive connection between mathematical statements. In mathematics, argumentation is extensively done for proving mathematical theorem. Every new theorem has to undergo a proof process to verify its validity in solving mathematical problems. Argumentation is defined as an activity that coincides with proof or justification. However, it is a broader idea and perceived to be a crucial component in learning mathematics [5], [10], [11]. This activity leads students to reflect upon and clarify the ideas, the concept of mathematical relationships, and mathematical arguments [12].

The ability of argumentation has to be honed to strengthen students' critical thinking [13]. Such skills will be useful in resolving problems, making a decision and being accountable for it. In reality, however, formal schools have not emphasized the development of such skills, especially in mathematics. Concerning with this issue, a preliminary study was done to find out students' initial knowledge about arguments. It was conducted in a state senior high school in Pasuruan, East Java, 
Indonesia. Based on the finding, it can be concluded that the majority of students do not understand or cannot distinguish either a text is an argument or not. Despite several students had correct answer in their worksheet, yet they failed to explain the concept of argument during the interview.

The key in argumentation is the ability to develop high-quality arguments. These arguments are measurable, which is by proving their validity [14]. An argument is claimed valid if at the time each premise is substituted with any particular statement, the results of all the premises are true, thus the conclusion is also true. Conversely, despite all premises are true but there are false conclusions, the argument is invalid. In addition, high-quality arguments consist of statements with facts, reasoning that connects data with statements and is supported by knowledge, and reinforcement of arguments [15]. Therefore, an instructional method that will improve students' mathematical argumentation abilities becomes a necessity.

One of extensive method to improve students' critical thinking skills is the argument mapping. It helps to disclose the logical structure inferred from an argument [16]. The structure of the argument consists of claim as a statement or decision stated by in the argumentation; data as the facts that support the statement, warrant as an explanation of the relationship between data and statements, qualifiers as certain condition to state the truth of a statement, and backing as the basic assumption to support the warrant, rebuttal as a statement that refutes the data [17].

Argument maps illustrate the logical structure in the box and arrow form, where premises/conclusions are supported by reasons contained in a distinctive box. In the mapping, the criteria of the argument developed in an argumentation will be clearly identified. Previous study has exposed this method as a means to prompt the development of arguments hence students are able to gain experience analyzing and evaluating the criteria for constructing valid arguments. Several steps to construct valid arguments, namely: identifying mathematical text, providing data, making premises, devising mathematical model, and proving it using truth table [14].

Based on the description above, the research problem of this study is: "Does the implementation of argument mapping improve students' mathematical argumentation skills?" Essentially, this study aims to investigate the students' mathematical argumentation skills before and after the implementation of argument mapping and the extent of the improvement in students' mathematical argumentation skills after the implementation of argument mapping.

\section{Methods}

In the present study, a quasi-experiment with a quantitative approach is employed. The population was the students of Class X of the Natural Sciences Program at a State Senior High School in Pasuruan, East Java, Indonesia. The sample of the study was selected using purposive sampling technique. This class was chosen since the students had relatively low score in mathematics. Totally, there were 36 students.

A set of learning tools was compiled, including the student's worksheet/LKS. This worksheet is intended to improve students' mathematical argumentation skills through argument maps. These maps adopt the Revised Bloom's Taxonomy [18], which is used to identify argument-not argument (C1), explain arguments (C2), draw conclusions based on premises (C3), reduce/add premises to supports conclusions (C4), claim valid-invalid arguments (C5), and develop and construct valid arguments (C6).

In the data collection stage, written test techniques was employed to obtain the data about students' mathematical argumentation skills in proving valid arguments. The test was carried out twice: after and before the implementation of argument mapping. Pre-test revealed students' initial skills while posttest showed the outcome of the method.

The instrument used in this study was a test of mathematical argumentation skills. It consisted of five items of description to prove valid arguments. Questions were designed and based on the components of argument proposed [14]. Prior to the test, this instrument was validated by Mathematics Education lecturers at Universitas Negeri Malang as the experts.

Data analysis of students' mathematical argumentation skills was initiated by classifying the capacity of students based on the score of the test. The classification is presented in Table 1.

Table 1. Criteria of Students' Mathematical Argumentation Skills

\begin{tabular}{cc}
\hline Internal Score & Category \\
\hline $85 \% \leq K P M \leq 100 \%$ & Excellent \\
\hline $75 \% \leq K P M<85 \%$ & High \\
\hline $55 \% \leq K P M<75 \%$ & Low \\
\hline $0 \% \leq K P M<55 \%$ & Very low \\
\hline
\end{tabular}

To determine the improvement in students' skills before and after the implementation of argument mapping, the scores obtained from the pre-test and post-test were compared. Furthermore, to test whether the difference between the pre-test and posttest scores was significant, a statistical test using the Wilcoxon Signed-Rank Test was carried out. This 
test was chosen due to the abnormal distribution of data, thus a non-parametric statistical test was considered more appropriate. The data analysis process used SPSS at 5\% level of significance $(\propto=$ 0.05). The research hypothesis is that there is a significant difference between the score of pre-test and post-test. If the post-test score of students' mathematical argumentation skills is higher than the pre-test, the difference is significant. It implies that the implementation of the argument maps is effective to improve such skills.

\section{Result and Discussion}

The analysis of the data retrieved from mathematical argumentation skills test, which indicates students' ability in constructing valid argument, is presented in Table 2 .

Table 2. Student's Mathematical Argumentation Skills

\begin{tabular}{ccc}
\hline \multirow{2}{*}{$\begin{array}{c}\text { Criteria of Argumentation } \\
\text { Skills }\end{array}$} & \multicolumn{2}{c}{ N (\%) } \\
\cline { 2 - 3 } & Pretest & Posttest \\
\hline Excellent & $8 \%$ & $22 \%$ \\
\hline High & $22 \%$ & $61 \%$ \\
\hline Low & $13 \%$ & $17 \%$ \\
\hline Very low & $57 \%$ & $0 \%$ \\
\hline
\end{tabular}

Table 2 reveals the majority of students, approximately $57 \%$, have low level of argumentation skills. Meanwhile, after the instructional method using the argument maps, the percentage of students categorized into high skills increased into $61 \%$ while excellent students increased into 22\%. Despite $17 \%$ of them are classified into low skills group, none are included in very low skills group.

Furthermore, the achievement of students' mathematical argumentation skills based on the Wilcoxon signed-rank test analysis is demonstrated in Table 3.

Table 3. Rank of Student's Mathematical Argumentation Skills

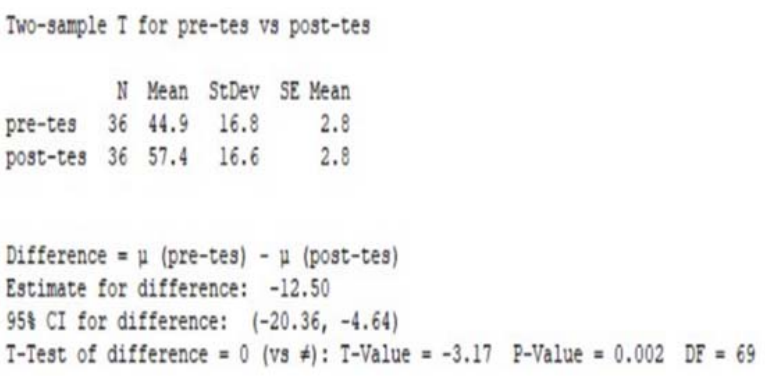

Table 3 shows the mean of the pretest score is 44.9 with a standard deviation of 16.8. Meanwhile, the mean of the posttest score is 57.4 with a standard deviation of 16.6, indicating the mean of the posttest is higher than that of the pretest with a difference of 12.5. To statistically prove the differences between the means, an independent $t$-test was carried out.

The results of the t-test indicate $t$-value of -3.17 with degree of freedom of $69, p$-value of 0.002 or less than the critical limit of $\propto=0.05$. Thus, it can be claimed that there is significant difference in the students' mathematical argumentation skills after and before the implementation of argument mapping.

Furthermore, in addition to obtain the data on the improvement of students' argumentation skills, the results of the test are also examined for specifying the components of the argumentation skills. A description of student's capacity in relation with the components of argumentation skills is presented in Table 4.

Table 4. The Components of Argumentation Skills and the Results of Pretest-Posttest

\begin{tabular}{lcc}
\hline \multicolumn{1}{c}{$\begin{array}{c}\text { Components of Mathematical } \\
\text { Argumentation Skills }\end{array}$} & \multicolumn{2}{c}{$\begin{array}{c}\text { Number of Students } \\
\text { Achieving Indicators }\end{array}$} \\
\cline { 2 - 3 } & Pretest & Posttest \\
\hline $\begin{array}{l}\text { Identifying argument/non- } \\
\text { argument (C1) }\end{array}$ & 36 & 36 \\
\hline $\begin{array}{l}\text { Explaining argument/non- } \\
\text { argument (C2) }\end{array}$ & 30 & 36 \\
\hline $\begin{array}{l}\text { Drawing conclusion after the } \\
\text { premises (C3) }\end{array}$ & 17 & 32 \\
\hline $\begin{array}{l}\text { Reducing/adding premises to } \\
\text { support conclusion (C4) }\end{array}$ & 9 & 22 \\
\hline $\begin{array}{l}\text { Concluding the validity of an } \\
\text { argument (C5) }\end{array}$ & 3 & 22 \\
\hline $\begin{array}{l}\text { Developing and constructing } \\
\text { valid argument (C6) }\end{array}$ & 1 & 16 \\
\hline
\end{tabular}

Table 4 provides the data classically, that the students' mathematical argumentation skills in each component have improved. It excludes component $\mathrm{C} 1$, in which prior to the argument mapping, the entire students have been able to identify arguments/not arguments. In component $\mathrm{C} 2$, there is an increase of $17 \%$, in which the students are able to explain about arguments/not arguments. In component $\mathrm{C} 3$, there is an increase of $14 \%$, in which the students are able to draw conclusions after the premises. In component $\mathrm{C} 4$, there is an increase of $58 \%$, in which the students are able to reduce/add to the premise to support conclusions. In component $\mathrm{C} 5$, there is an increase of $53 \%$, in which the students are able to validate arguments. In component C6, there is an increase of $41 \%$, in which the students are able to develop and construct valid arguments. 
The ability to develop and construct valid arguments is associated to the comprehend concepts. The argument maps have assisted students in understanding the concept of arguments through the process of creating concepts and interpreting data. Subsequently, certain principles are required to resolve a new situation. During the conception process, students will exercise their argumentation skills. Such skills will automatically improve the communication skills or the ability to express their opinions based on the acquired information or data. Written argumentation skills are useful for enhancing students' scientific knowledge and writing skills [19]. Meanwhile, process of gathering various components is essential to develop an argument.

The effectiveness of argument mapping is to visualize logical thinking structure of an argument. Beside that, critical thinking particularly in argumentation can be enhanced through experiences in express ideas, both spoken and written [20]. This Argument mapping is focused on the connection of logical data, reasoning or drawing conclusion between the propositions [15]. It will stimulate learners to exercise critical thinking in drawing a conclusion based on string and valid arguments.

Based on the results of the data analysis, the implementation of argument mapping in the instructional method is able to improve students' mathematical argumentation skills. It indicates that this method successfully assists students in linking their ideas/opinions with data/facts that support those ideas/opinions.

Argument maps identify abstract assumptions and components that build an argument. With the identification process in developing an argument, students are stimulated to engage in and enhance their mathematical argumentation skills.

Despite the fact that $17 \%$ of students are still categorized in low skills' group, the main issue has been recognized, namely the failure in proving valid arguments. It is caused by the inability of students to model mathematical problems into mathematical symbols, as well as making mathematical model from an argument. Consequently, students face difficulties in proving valid arguments. In general, the argument maps can be used as an alternative to learning mathematics, particularly to improve students' mathematical argumentation skills on argument problems.

\section{Conclusion}

This study has discussed the implementation of argument mapping in relation with the students' mathematical argumentation skills. Several conclusions can be formulated based on the findings. First, the mathematical argumentation skills of the majority of students are categorized into low skills' group, prior to the implementation of argument mapping in learning mathematics. Most of them are only able to solve the argument problem - from the stage of identifying the argument/not argument to the stage of drawing conclusion after the premises. Second, the mathematical argumentation skills of the majority of students are categorized into excellent and very high skills' group after the implementation of argument mapping. It has been identified through an identification model that has been carried out by the subject. In this stage, most students are able to conclude whether the argument is valid or invalid. Moreover, several students are able to construct valid arguments. Third, the students' mathematical argumentation skills after the implementation of argument mapping show a significant difference.

Several recommendations are propounded based on the findings of this study. First, the argument mapping can be an alternative method to improve students' mathematical argumentation skills. Second, it is suggested to involve a control class for highlighting the effectiveness of the argument mapping in the actual situation. Third, similar research should be carried out by involving a broader population and sample size to obtain a more general result.

\section{References}

[1] Jonassen, D. H. (2010, September). Research issues in problem solving. In 11th International Conference on Education Research.

[2] Brodie, K. (2010). Classroom practices for teaching and learning mathematical reasoning. In Teaching mathematical reasoning in secondary school classrooms (pp. 73-85). Springer, Boston, MA.

[3] Krummheuer, G. (2013). The relationship between diagrammatic argumentation and narrative argumentation in the context of the development of mathematical thinking in the early years. Educational Studies in Mathematics, 84(2), 249-265.

[4] Simon, S., Erduran, S., \& Osborne, J. (2006). Learning to teach argumentation: Research and development in the science classroom. International journal of science education, 28(2-3), 235-260.

DOI: $10.1080 / 09500690500336957$.

[5] Krummheuer, G. (2007). Argumentation and participation in the primary mathematics classroom: Two episodes and related theoretical abductions. The Journal of Mathematical Behavior, 26(1), 60-82.

[6] Conner, A., Singletary, L. M., Smith, R. C., Wagner, P. A., \& Francisco, R. T. (2014). Identifying kinds of reasoning in collective argumentation. Mathematical Thinking and Learning, 16(3), 37-41.

[7] Whitenack, J. W., \& Knipping, N. (2002). Argumentation, instructional design theory and students' mathematical learning: a case for coordinating interpretive lenses. The Journal of Mathematical Behavior, 21(4), 441-457. 
[8] Yackel, E. (2002). What we can learn from analyzing the teacher's role in collective argumentation. The Journal of Mathematical Behavior, 21(4), 423-440.

[9] Yackel, E., Rasmussen, C., \& King, K. (2000). Social and sociomathematical norms in an advanced undergraduate mathematics course. The Journal of Mathematical Behavior, 19(3), 275-287.

[10] Staples, M. E., Bartlo, J., \& Thanheiser, E. (2012). Justification as a teaching and learning practice: Its (potential) multifacted role in middle grades mathematics classrooms. The Journal of Mathematical Behavior, 31(4), 447-462.

[11] Kwon, O. N., Ju, M. K., Kim, R. Y., Park, J. H., \& Park, J. S. (2013). Design research as an inquiry into students' argumentation and justification: Focusing on the design of intervention. Educational design research-Part B: Illustrative cases. Enschede, The Netherlands: SLO.

[12] Ontario. Ministry of Education. (2005). The Ontario Curriculum, Grades 9 and 10: Mathematics, 2005. Ministry of Education.

[13] Elbrink, M. K. (2007). Analyzing and addressing common mathematical errors in secondary education: an honors thesis (HONRS 499), Undergrad. Math. Exch., 5(1), 2-4.
[14] Indrawatiningsih, N., As'ari, A. R., \& Sa'dijah, C. Mathematical Argumentation Ability: Error Analysis in Solving Mathematical Arguments. Journal for the Education of Gifted Young Scientists, 8(2), 711-721.

[15] Dawson, V., \& Venville, G. J. (2009). High-school Students' Informal Reasoning and Argumentation about Biotechnology: An indicator of scientific literacy?. International Journal of Science Education, 31(11), 1421-1445.

[16] Wingate, U. (2012). 'Argument!'helping students understand what essay writing is about. Journal of English for academic purposes, 11(2), 145-154.

[17] Toulmin, S. E. (2003). The Uses of Argument , Updated Edition. New York: Cambridge University Press.

[18] Anderson, L., \& Krathwohl, D. R. (2010). Taxonomy for Learning Teaching and Asswssing. New York: David McKay Company.

[19] Bathgate, M., Crowell, A., Schunn, C., Cannady, M., \& Dorph, R. (2015). The learning benefits of being willing and able to engage in scientific argumentation. International Journal of Science Education, 37-41.

[20] Curto, K., \& Bayer, T. (2005). Writing \& Speaking to Learn Biology: An Intersection of Critical Thinking and Communication Skills. Bioscene: Journal of College Biology Teaching, 31(4), 11-19. 